\title{
Analysing Indian G-Secs with a Predictive Approach
}

\author{
Serin Josy Thomas, ${ }^{*}$ Sahana Madhanagopal ${ }^{\dagger}$ and \\ Bikramaditya Ghosh ${ }^{\ddagger}$
}

\begin{abstract}
The bond movement being observed keenly by the business communities across the world is primarily because of the fact that large organizations require a huge sum of money which cannot be met in the form of bank loans alone. The solution is to raise money from the public by issuing bonds. It is of equal interest to the investors because bonds are fixed income securities. In this market it is imperative to understand the interplay of macroeconomic factors such as inflation levels, interest rates, foreign exchange rates, purchasing power parity, price movements, monetary and fiscal policies. The rationale behind the decision to invest in a particular bond is directly influenced by the present value of the bond. This paper aims to build a model using Panel Data Regression to predict the present value of the bonds by considering the components of the term structure such as interest rates, maturity, bond yield etc.
\end{abstract}

Keywords: Bonds, Maturity, Inflation, Risk, Present Value, Bond Yield, Interest Rates.

\footnotetext{
*Western Michigan University, USA; serin.josy@wmich.edu

† Western Michigan University, USA; sahana.madhanagopal@wmich.edu

‡ Christ University, Bengaluru, India;

bikramaditya.ghosh@christuniversity.in
} 


\section{Introduction}

The present global scenario is that the central banks across the world are tightening their monetary policies with the Federal Reserve leading the bandwagon. It is anticipated that there is another Federal rate hike in the offing. The alarm this has created amidst the bondholders is evident as there is a marked increase in the selling of the government bonds and this anxiety is to stay for a while as the central banks are giving out clear signals that the era of "extraordinary monetary policy" is coming to an end. It is predicted that the 10-year bonds are going to be particularly taxing as the rates of these bonds are escalating quicker than expected. The fear factor induced by the recent political, social and economic events will prompt the investors to get rid of the risky components in their investment portfolio and go for a safe option such as the US Treasury bonds which is known to be the safest and likewise, other government bonds that are also comparatively safer than the stock markets. But the current trend of increasing interest rates might influence the preference of the investors to go for short term bonds rather than long term ones to shield themselves from the volatility of the interest rates. Individual bonds with acceptable credit quality of the issuers is also another commonly voted option.

While this process of normalizing the financial environment that has been too easy too long is seen as a threat by some of the veteran investors, there is an alternative opinion that this tightening of the rope will bring back the bond market to reality. If this trend continues, the bond market might once again become the favoured investment destination as new bonds will be issued with higher coupon rates.

Looking at the $\$ 750$ Billion Indian debt market, it is becoming the sweet spot for global investors mainly due to the structural reforms laid out by the present government, higher yield and a well anchored exchange rate in comparison with the other emerging markets. Despite a possible brief stand-still due to the loan waivers provided for the indebted farmers, the Indian market will continue to attract foreign investment due to the remarkable political stability and the sustained efforts by the Reserve Bank of India to keep the consumer price inflation under control. It is to be noted 
that the investors have earned $7.5 \%$ by the way of borrowing in the US and investing in the Indian assets this year so far. One of the Singapore based research analyst said that "Other markets may have higher absolute yields, but there aren't many offering the kind of yields seen in India that also have the steady environment necessary to engender greater investor confidence."

In order to make prudent decisions especially if it is a debt portfolio given the current circumstances, it is important to assess the value of the bond. By an extensive study of literature, it is found that the domain of predictive modelling with respect to bond valuation is less explored. Hence this paper is an attempt to add a statistical dimension to this investment conundrum.

\section{Objectives}

1. Prediction of Present Values of 10-year Government Security bonds

2. To determine interest rate movement of bonds by observing Negotiated Dealing System - Order Matching Segment (NDS - OM).

3. To derive movement of interest rates using econometrics.

\section{Literature Review}

The bond market is one of the widely researched areas. The dynamism and the risk associated with the factors affecting the value of the bonds have attracted the scholars across the world. In order to address the objectives of this study, it was imperative to understand and appreciate the work done by the fellow researchers in this domain. Given below is the summary of the detailed study done on related articles.

A bond is associated with several risks. With an objective to show that even bonds with short maturities are impacted by credit spreads, a research was done on a bond valuation model considering both credit as well as liquidity risks ( $\mathrm{Fu}$, Wang, \& Wang, 2012). In an elaborate study to analyze the risk in bonds with respect to time variation, the extent to which return on stock and the return on bonds vary together, growth of consumption and 
the volatility in the bond returns was used to meet the objectives (Viceira, 2012). The results revealed that the changes in the values of the interest rates of the short-term bonds rates and that of the spread on their yield spread were positively correlated with the changes in the bond risks and volatility of the returns. The yield spread was representative of the business conditions and the uncertainty in the economy was reflected by the short-term rates. An increase in yield spread is found to be negatively correlated with the inflationary risks associated with the bonds while being positively related to the risk of discount rates. Another research was done to find a relationship between two types of risks namely the price risk and the terminal value risk arising from interest rate volatility and the results thus obtained showed that both are inversely related. Mitigation of one risk increases the other by the same amount (Kim, 2011)

The Australian bond market was studied (Fang \& Hung, 2014)to find out if the idiosyncratic risk or the unsystematic risk affects the bond prices in the non-government bond sector. Idiosyncratic risk has two components: dispersion and volatility. The statistical analysis done on the data obtained using panel data regression and Newey West error detector revealed that the idiosyncratic dispersion of the share prices with a one week lag shares a positive relationship with the bond prices. On the other hand, the volatility component did not seem to affect the prices. In an experimental study on the fluctuating interest rates, the cross-sectional data of bond prices was used in finding out the possibility of predicting this volatility by regressing it against the level, slope and curvatures of the bond yield. (Collin-Dufresne, Goldstein, \& Jones, 2009). The predictive model built using point estimates, parameter estimates and GARCH model performed well in case of unconditional volatility structure and long-maturity volatility. Since short and long volatilities are driven by different set of components, the short rate volatility could not be explained by the factors under study.

A predictive analysis was done on the Euribor future options market to use the interest rate risks associated with options to forecast risk premiums and state prices. Both parametric and nonparametric tests were utilized to identify from the state price 
densities if investors are more concerned with the risk involved in the steadily increasing rates of interest and the densities of the options that are neutral to risk. (Ivanova \& Puigvert Guti??rrez, 2014). The time dependent interest rate risk was modelled by utilizing the data on the US Treasury bonds. (Hautsch \& Ou, 2012). A linear equation relating yield factors, factor volatilities \& macroeconomic fundamentals was obtained using Markov chain Monte Carlo techniques. The analysis revealed that in times of high inflation \& capital utilization there is low volatility in the interest rate values which could be attributed to monetary policy intervention. Other similar such observations make one to conclude that factor volatility is even closely correlated to macroeconomic variables than the factors themselves

Some of the international researchers of high repute put forward the view that open interest rate is a more reliable indicator of the economic activity and the trends in the asset prices compared to the future prices (Hong \& Yogo, 2012). Futures price tends to fluctuate based on the demand for hedging and hence are considered to be less reliable. Rate impacts almost all the markets like commodity, currency, stock and bond. It also predicts the returns amidst the limited risk absorption capacity in the futures market. There is a possibility that even a risk-free bond has some amount of price risk associated with it. In order to examine the possible sources of such a risk, some experts regressed Yield to maturity against changes in the short-term rates and changes in the interest rate volatilities (Longstaff \& Schwartz, 1993) and deduced that there are two such sources. One is the interest rate shift and the other is the changes in the bond market volatility. The latter was found to be the significant component of the total risk associated with the bond portfolio.

Different types of bonds to understand which type of bond will cater to different needs of the investor. An extensive research was carried out to examine if the coupon of the bonds affect the pricing, empirical duration (sensitivity to changes in treasury yields) and the spread (HYMAN, DOR, DYNKIN, HOROWITZ, \& XU, 2015). A comparative analysis of the spread convexity was made with that of the other bonds from the same issuer and used simple statistical tools to find if these parameters can affect the performance of the 
bond portfolio as a whole. The analysis showed that discount bonds have lower spread than premiums and are better cushioned from risk of default. They are less varying when the rates increase and become sensitive to falling rates whereas premiums show the opposite behaviour. In the long run when the rates tend to increase discount bonds would outperform the premium ones as they would show stability. A comparative analysis of the performance of the conventional treasury securities and the inflation-indexed treasury securities (TIIS) was carried out with respect to the US Bond market (Sack \& Elsasser, 2004). It was found that TIIS did not attract any significant investment amongst the American investors which could be attributed to several reasons- resistance in accommodating a new asset in their portfolio, less liquid compared to the nominal ones, consistently declining spread between the nominal and inflation adjusted yields are some of them. But since it is an emerging investment destination, there is scope for increase in TIIS value

While trying to understand the nuances of this highly unpredictable segment of the global market, researchers have also developed predictive models using several new techniques.

A modified spline technique in which smoothed splines with a roughness penalty that is variable with respect to the maturity of the bond was developed to estimate the forward interest rate curve from the coupon data of the bonds (Waggoner, 1997). A comparative analysis of the performance of the proposed model against that of Fisher and McCulloch was done. With varying roughness penalty, Fisher method performed better to predict prices of short term securities especially when a smoothed spline has to be employed. McCulloch approach is easier and quicker as it is linear compared to Variable Roughness Penalty (VRP) method. but VRP allows the amount of smoothness to be controlled. In order to value the securities that are highly sensitive to interest rates and hence to find the bond prices, the researchers developed a single factor model using the short rates (Black, Derman, \& Toy, 1990). Yield curve and volatility curves were taken as the input. This is also used to value the bond options by finding the option hedge ratios. A binomial tree approach was used to construct the short rate curve. 
An effort was made to introduce a new method using discrete duration to evaluate the interest rate sensitivity of bonds and to stress test with different types of bonds against basic duration and duration plus convexity methods. The new approach of using discrete duration performed well for long dated and low coupon bonds with nearly zero estimation error. There was clear domination over the exponential duration approach in all simulations. It even outperformed duration plus convexity approach in case of long term zero coupon bonds. (Bajo, Barbi, \& Hillier, 2013)

To have a better understanding of the bond market, some scholars felt the need to simultaneously study the equity market as both the markets are very much inter-dependent. In the process, the impact of the macroeconomic variables on the performance of these markets was also scrutinized in order to have a holistic understanding of the scenario.

To assess the value of the Government bonds and to find out how efficiently are the price changes captured due to the volatility of the interest rates using convexity, duration and the modified duration of the bonds, some of the researchers made use of the data from Stock Exchange of Macedonia (Ivanovski, Stojanovski, \& Ivanovska, 2013). It was observed that duration and convexity together are better predictors of interest rate sensitivity of the bond prices than the duration alone as the predictor. T-bonds are not sensitive to interest rates because of persistent high demand from the investors to hedge a part of their portfolios and the market for government bonds is very narrow. Capital Asset Pricing Model, arbitrage pricing theory and the OLS regression model were deployed to deduct the relationship between the movement of stock returns and the various market forces with respect to the data from the Stock Exchange of Kenya. Variables like money supply, inflation, exchange rates were found to play significant role while interest rate was not found to be a convincing factor to determine the stock returns in the long run. (Muriu \& Nduga, 2014).

In a comparative study of the bond and stock markets, some of the experts used time series regression to find out the risk factors that significantly explain the variation in the average return of stocks and bonds and also to determine if the important variables of bond 
return help explaining stock return and vice-versa (Fama \& French, 1993). Five factors were found to be common to both the markets: the stock market factors include: Size, market factor and BE/ME ratios; Maturity \& default risk premium were the bond market specific factors. Both the stock and the bond markets were explored to find out the relationship between inflation and stock prices and to analyse if inflation causes damages to the real economy by driving up the dividend-price ratio when it falls or if it increases the equity premium by making the investors more risk averse (Campbell \& Vuolteenaho, 2004). The possibility that the stock market investors fail to understand effect of inflation and wrongly extrapolate growth rates in conditions of changing inflation rates was also given due consideration. The loglinear dynamic valuation framework used for analysis revealed a high correlation between inflation and mispricing. It validated the possibility that investors tend to extrapolate past nominal growth rates without adjusting for inflation. Stabilization of inflation will reduce volatility of mispricing and thereby improve the efficiency of stock markets.

The Theoretical framework of Deaton \& Laroque and panel GARCH model were used to understand the extent to which the interest rates exert influence on the prices of the commodities and their volatilities. Both the theoretical and empirical results were found to be in harmony with each other. The volatility in the prices is smoothened out as the interest rates decline. The correlation among prices seemed to increase with rate cuts amidst the prevalence of market shocks rather than the firm or industry specific shocks. This was particularly evident from the trend in metal prices (Gruber \& Vigfussion, 2012).

Some researchers examined systematically to find out how the prices of the bonds and the yield curve dynamics are affected by the macro economic variables (Ang \& Piazzesi, 2003). The first macro variable consisted of inflation measures like CPI, PPI and PCOM. The second one was related to employment \& industrial production. Vector Auto-regression Model, Impulse Responses and Variance Decomposition methods were employed to deduce that macro factors explain about $85 \%$ variation in bond yields, fully explaining the movement at short end and middle of the yield curve, but only $40 \%$ of the long end. Effect of inflation shock is 
strongest at the short end. The cause-effect relation between the rate of inflation and the interest rates and also between the inflation rate and the unemployment rate with data (1997-2013) from the Romanian National Bank was studied using simple linear regression model. It was found that a direct relation existed between the interest rate and the inflation rate whereas inflation and unemployment rates were inversely related. Hence interest rate can be used as a tool by the banks to control inflation and in turn to keep the unemployment levels under control (Cioran, 2014).

One of the researches on the bond market was done to estimate the trend of interest rates and the inflation levels in the future by using the historical prices of the British Government bonds- both nominal and index-associated(Barr \& Campbell, 1997)using a simple regression analysis. From the results obtained it was clear that the real interest rates showed more volatility in the short term than in the long term. The anticipated fluctuations in the long horizon inflation rates is responsible for $80 \%$ of the changes in nominal rates for longer duration. In Short-Term, a negative correlation was found between the changes in Real interest rates and the Inflation Rates. But with the expansion of the time horizon, these two quantities tend to become uncorrelated and then gradually become positively correlated. Stochastic calculus was used to derive at a link between the short term volatility and the prices of the bonds and hence assess the impact of sensitivity to arbitrage on the interest rates (Mele, 2003). Some of the properties of bonds were established in the course of this research: bond prices tend to decline when the short maturity interest rates are considered; with increase in aversion to risk the term structure the interest rates show a steady increase; at shorter maturities, when there is a significant market-risk premium, there is an inverse relationship between bond prices and their associated volatilities.

A research to find the link between the dynamics of the exchange rate in the short run and the macroeconomic factors under arbitrage free circumstances in the international market was carried out with an assumption of a two-country world: US and Euro. The factors considered were outputs, inflation and the short-term interest rates (Yin \& Li, 2014). A non-linear relationship was derived between the macroeconomic factors, innovations and 
exchange rate variations using stochastic discount factor and unscented Kalman filter. The monthly exchange rate and the observed data were found to be correlated to the extent of $76 \%$ and the $\mathrm{R}^{2}$ value was about $57 \%$. An inquiry into the dynamics of the global bond market was done to investigate the extent to which the bond yield movement of various countries, risk premiums, interest rates and the other macroeconomic parameters are influenced by the external disturbances on the foreign exchange rates (Pericoli \& Taboga, 2012). The volatility associated with the exchange rates are primarily explained by the time-dependent risk premiums of the bonds. A currency appreciates when investors expect a large capital gains on the Long-Term bonds denominated in that currency.

To understand the working of Panel Data Regression, research papers involving this statistical technique were also studied:

A study was done based on the data obtained from the publicsector banks in India to predict their Earnings Per Share (EPS) using the artificial neural network (ANN) and panel data regression (PDR) (Ghosh, Mc, \& Ramachandran, 2016). Results obtained by applying both the methods on the data under study were highly robust with the adjusted R-Squared value being as high as $99 \%$. There were two independent variables that were clearly significant namely the Graham's number and the Book value. The ROA and the PAT variables can also be considered significant although not as efficient as the first two. Despite the availability of a plethora of investment alternatives, there is found to be a common fear factor amidst the investing communities. This was revealed through the observation of the BRICS and the UK markets. The researchers established a link between this fear factor and the consequent behaviour of the marketers using Generalized Method of Moments model (Ghosh, Le Roux, \& Ianole, 2017). One can conclude from the results of this study that, despite the geographical, political, educational and financial diversity of the sample under observation, high volatility in the market seemed to have influenced the investors to move some of their assets to safe haven such as gold. 
Serin Josy Thomas et al. Analysing Indian G-Secs with a Predictive Approach

\section{Research Methodology}

This is an exploratory research to find out the significant parameters in the prediction of the present values of the government security bonds. Mid-term and long-term bonds with tenure of 10 years are considered for the purpose of this study. The bond market was observed for a week and three bonds were chosen as the sample set. They are:

\begin{tabular}{lr}
\hline Bonds & Code \\
\hline $7.59 G S 2026$ & 1 \\
6.97GS2026 & 2 \\
7.61GS2030 & 3 \\
\hline
\end{tabular}

In the course of this work, various indicators that influence the bond market are also observed:

i) GDP - 2095 (YoY-7.00\% \& QoQ - 1.6\%)

ii) Interest rate: $6.25 \%$

iii) Inflation rate: $3.65 \%$

iv) Currency rate: 65.25

v) CPI: 130.60

vi) Trade deficit: $\$ 10.4$ Billion

The bond values given in the RBI NDS-OM were tracked for 16 days (two alternative weeks) from March 03,2017 to April 07,2017 to understand the movement of bonds in order to assess the impact of coupon rates and inflation on the valuation of bonds. Finally, Panel Data Regression (fixed effects) was applied to quantify the above relationship by building a uniform model that can best fit the actual and the predicted values. 
Table 1 Study output

Dependent Variable: PV

Method: Panel Least Squares

Date: 05/18/17 Time: 19:35

Sample: 3/02/2017 4/07/2017

Periods included: 16

Cross-sections included: 3

Total panel (balanced) observations: 48

\begin{tabular}{lllll}
\hline Variable & Coefficient & Std Err & t-Stat & Prob. \\
\hline C & 136.5158 & 4.487558 & 30.42096 & 0 \\
LTY & -4.816911 & 0.639291 & -7.534767 & 0 \\
TRADES & -0.000746 & 0.000483 & -1.545476 & 0.1339 \\
TTA & $5.83 \mathrm{E}-05$ & $4.96 \mathrm{E}-05$ & 1.176073 & 0.2498 \\
\hline
\end{tabular}

\section{Effects Specification}

Cross-section fixed (dummy variables)

Period fixed (dummy variables)

\begin{tabular}{lrll}
\hline R-squared & 0.994977 & Mean dependent var & 102.4896 \\
Adjusted R-squared & 0.991257 & S.D. dependent var & 1.215457 \\
S.E. of regression & 0.113652 & Akaike info criterion & 1.211721 \\
Sum squared resid & 0.348751 & Schwarz criterion & 0.393071 \\
Log likelihood & 50.08131 & Hannan-Quinn criter. & 0.902352 \\
F-statistic & 267.4291 & Durbin-Watson stat & 1.762535 \\
Prob (F-statistic) & 0 & & \\
\hline
\end{tabular}

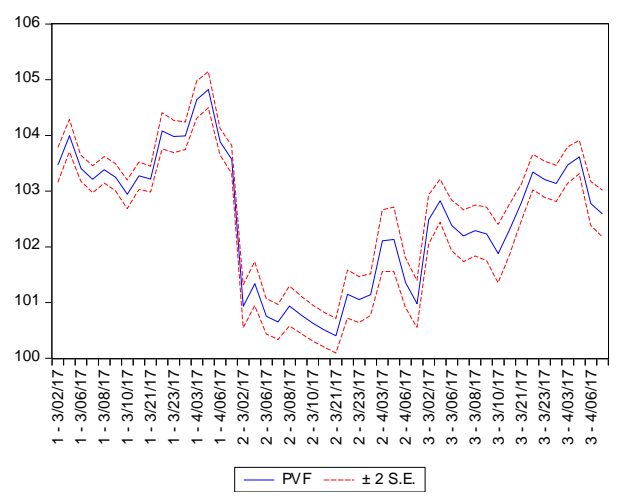

Fig 1 Forecasted PV with Standard Error variation 
Serin Josy Thomas et al. Analysing Indian G-Secs with a Predictive Approach

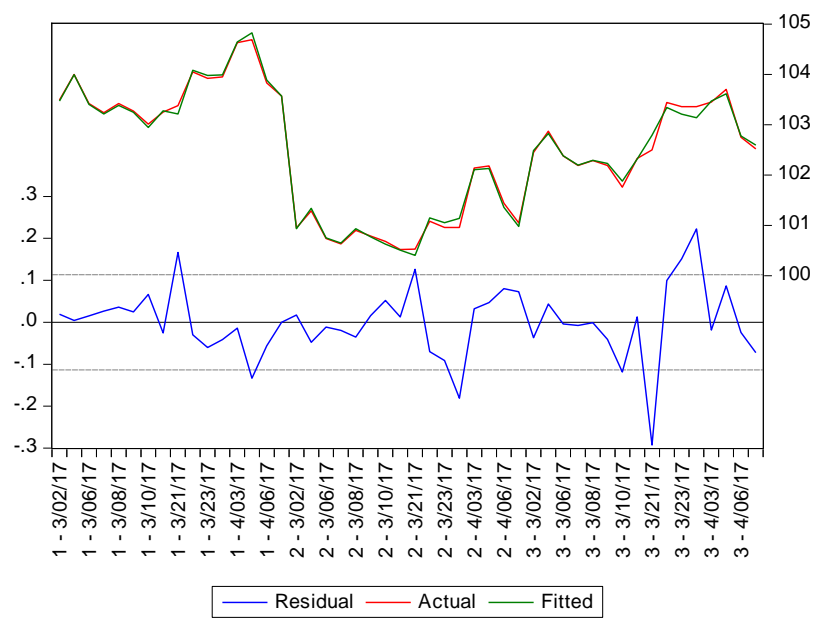

Fig 2 Actual and the fitted Present values with residuals

Estimation Equation:

$\mathrm{PV}=136.515847019-4.81691138106^{*} \mathrm{LTY}-0.000745901525707^{*}$ TRADES + $5.83357400895 \mathrm{e}-05^{*}$ TTA

\section{Analysis and Interpretation}

Long Term Yield (LTY): It is one of the regressing variables used to obtain the model. It can be seen that the significance or the p-value of this variable is 0.00 as per the results obtained above. It can alternatively be looked at as the occurrence of the bond being $100 \%$. This indicates that it is one of the key parameters in finding the present value (PV) of a bond. The negative sign of the coefficient indicates an inverse relationship with the present value. Hence, the PV will be higher for smaller values of LTY

Trade - Probability of Trade $=13 \%$. Therefore, occurrence of trade $=(1-13 \%)=87 \%$.

TTA - Probability of Trade $=25 \%$; Therefore, occurrence of trade $=$ $(1-25 \%)=75 \%$. 
It is evident from the p-values of Trade and TTA that they are not the significant factors to be considered to compute the PV of the bonds since both the value are beyond the 95\%( confidence interval), P.V value of bonds does not depend on trades and TTA value.

Adjusted R-squared: Since the analysis is done using multiple regression the adjusted R-Squared value is the better measure of the goodness of fit. Adjusted R-squared=99.12. The equation will hold good for 99.12 times out of 100 . It can be inferred that the model is highly efficient in predicting the PV.

Prob $($ F-statistic $)=\mathbf{0}$. These again is indicative of a robust model as the null hypothesis that all the coefficients are zero is rejected. It is also evident from the regression equation and the graph that the data follows a certain trend and is not spurious in nature. Even the Durbin Watson statistic value validates the presence of positive serial autocorrelation amongst the data points under study.

Log likelihood - 50.08. Ideal log likelihood should be below 100 . Here it is 50 which proves that the equation is competent. The values of Akaike Information Criterion, Schwarz Criterion and Hannan-Quinn Criterion obtained in the result shows that the predictive model is high in quality and is robust.

The Root Mean Squared Error, Mean Absolute Error and the Mean Absolute Percent Error values are low and well within the permissible limits. This is also graphically validated as the Actual and fitted lines are almost moving together.

\section{Findings and Recommendations}

Interestingly we've found that yield holds the key and not the trades or the trade volume (TTA). Yield depends on the interest rate outside; hence indirectly this model echoes the age-old knowledge that states "Bonds do move in an inverse direction with interest rates outside". Coefficient of LTY is negative indicating inverse relationship with the present value of the bond. Often analysts in credit offer undue importance to trades and volume of trade (TTA) in Bonds. This study nullifies that recommendation and firmly establishes the fact that, both trades and volume (TTA) are in no way connected to determine the present value. 
Furthermore, in can be recommended to all the bond traders to follow the model (that emerged out here in this study) and note that despite relative low impact of both trades and volume (TTA) they are still considered. This is because of the fact that impact of parameters does keep change in long horizon. Traders are recommended therefore to re-calculate the equation after each passing year (following the same methodology). That will ensure consistently higher accuracy in decision making. Last but not the least; the last yield is crucial but not the average yield. Hence, a rolling calculation will ensure very high level of precision.

\section{References}

Ang, A., \& Piazzesi, M. (2003). A no-arbitrage vector autoregression of term structure dynamics with macroeconomic and latent variables. Journal of Monetary Economics, 50(4), 745-787. https:// doi.org/ 10.1016/S0304-3932(03)00032-1

Bajo, E., Barbi, M., \& Hillier, D. (2013). Interest rate risk estimation: a new duration-based approach. Applied Economics, (45), 2697-2704. https:// doi.org/10.1080/00036846.2012.667552

Barr, D. G., \& Campbell, J. Y. (1997). Inflation, real interest rates, and the bond market: A study of UK nominal and index-linked government bond prices. Journal of Monetary Economics, 39(3), 361-383. https:// doi.org/10.1016/S0304-3932(97)00027-5

Black, F., Derman, E., \& Toy, W. (1990). A One-Factor Model of Interest Rates and Its Application to Treasury Bond Options. Financial Analysts Journal, 46(1), 33-39. https:// doi.org/10.2469/faj.v46.n1.33

Campbell, J. Y., \& Vuolteenaho, T. (2004). Inflation illusion and stock prices. In American Economic Review (Vol. 94, pp. 19-23). https:// doi.org/10.1257/0002828041301533

Cioran, Z. (2014). Monetary Policy, Inflation and the Causal Relation between the Inflation Rate and Some of the Macroeconomic Variables. Procedia Economics and Finance, 16(May), 391-401. https:// doi.org/ 10.1016/S2212-5671(14)00818-1

Collin-Dufresne, P., Goldstein, R. S., \& Jones, C. S. (2009). Can interest rate volatility be extracted from the cross section of bond yields? Journal of Financial Economics, 94(1), 47-66. https:// doi.org/ 10.1016/ j.jfineco.2008.06.007

Fama, E. F., \& French, K. R. (1993). Common risk factors in the returns on stocks and bonds. Journal of Financial Economics, 33(1), 3-56. https:// doi.org/10.1016/0304-405X(93)90023-5

Fang, V., \& Hung, C.-H. D. (2014). Corporate bond prices and 
idiosyncratic risk: Evidence from Australia. Journal of International Financial Markets, Institutions and Money, 33, 99-114. https:/ / doi.org/ 10.1016/j.intfin.2014.07.011

Fu, J., Wang, X., \& Wang, Y. (2012). Credit spreads, endogenous bankruptcy and liquidity risk. Computational Management Science, 9(4), 515-530. https:/ / doi.org/10.1007/s10287-012-0153-3

Ghosh, B., Le Roux, C., \& Ianole, R. (2017). Fear Estimation-Evidence from BRICS and UK. International Journal of Applied Business and Economic Research, 15(4),195-207.

Ghosh, B., Mc, K., \& Ramachandran, T. (2016). Asian Journal of Research in Business Economics and Management Asian Research Consortium PSU Bank Modeling-A comparative modeling approach involving Artificial Neural Network and Panel Data Regression. Asian Journal of Research in Business Economics and Management, 6595800037(62). https://doi.org/10.5958/2249-7307.2016.00037.2

Gruber, J. W., \& Vigfussion, R. J. (2012). Interest Rate and The Volatility and Correlation of Commodity Prices. International Institute for Sustainable Development. https://doi.org/10.1017/S1365100516000389

Hautsch, N., \& Ou, Y. (2012). Analyzing interest rate risk: Stochastic volatility in the term structure of government bond yields. Journal of Banking \& Finance, 36(11), 2988-3007. https:// doi.org/ 10.1016/ j.jbankfin.2012.06.020

Hong, H., \& Yogo, M. (2012). What does futures market interest tell us about the macroeconomy and asset prices? Journal of Financial Economics, 105(3), 473-490. https:// doi.org/ 10.1016/ j.jfineco. 2012.04.005

HYMAN, J. A. Y., DOR, A. B. E. N., DYNKIN, L. E. V, HOROWITZ, D., \& XU, Z. H. E. (2015). Coupon Effects on Corporate Bonds: Pricing, Empirical Duration, and Spread Convexity. Journal of Fixed Income, 24(3), 52-63. https://doi.org/10.3905/jfi.2014.24.3.052

Ivanova, V., \& Puigvert Guti??rrez, J. M. (2014). Interest rate forecasts, state price densities and risk premium from Euribor options. Journal of Banking and Finance, 48, 210-223. https://doi.org/10.1016/ j.jbankfin.2014.03.028

Ivanovski, Z., Stojanovski, T. D., \& Ivanovska, N. (2013). Interest Rate Risk of Bond Prices on Macedonian Stock Exchange - Empirical Test of the Duration, Modified Duration and Convexity and Bonds Valuation. Ekonomska Istrazivanja, 26(3), 47-62. https://doi.org/ 10.1080/ 1331677X.2013.11517621

Kim, S.-H. (2011). Interest Rate Risk of Bond Investment. Journal of International Business and Economics, 11(3), 123-128.

Longstaff, F. a, \& Schwartz, E. S. (1993). Interest Rate Volatility and Bond Prices. Financial Analysts Journal, 49(4), 70. https:// doi.org/ 10.2469/ 
Serin Josy Thomas et al. Analysing Indian G-Secs with a Predictive Approach

faj.v49.n4.70

Mele, A. (2003). Fundamental Properties of Bond Prices in Models of the Short-Term Rate. Review of Financial Studies, 16(3), 679-716. https://doi.org/10.1093/rfs/hhg011

Muriu, P., \& Nduga, W. (2014). The Impact of Macroeconomic Variables on Stock Prices Market Returns in Kenya. International Journal of Business and Commerce, 3(11), 1-26. https://doi.org/ 10.4038/ suslj.v6i1.1689

Pericoli, M., \& Taboga, M. (2012). Bond risk premia, macroeconomic fundamentals and the exchange rate. International Review of Economics and Finance, 22(1), 42-65. https:/ / doi.org/10.1016/j.iref.2011.08.008

Sack, B. P., \& Elsasser, R. (2004). Treasury Inflation-Indexed Debt: A Review of the U.S. Experience. FRBNY Economic Policy Review, May(1), 47-63. https://doi.org/10.2139/ssrn.325321

Viceira, L. M. (2012). Bond risk, bond return volatility, and the term structure of interest rates. International Journal of Forecasting, 28(1), 97117. https://doi.org/10.1016/j.ijforecast.2011.02.018

Waggoner, D. F. (1997). Spline Methods for Extracting Interest Rate Curves from Coupon Bond Prices. Ferderal Reserve Bank of Atlanta. https:// doi.org/10.2139/ssrn.86789

Yin, W., \& Li, J. (2014). Macroeconomic fundamentals and the exchange rate dynamics: A no-arbitrage macro-finance approach. Journal of International Money and Finance, 41, 46-64. https://doi.org/ 10.1016/ j.jimonfin.2013.10.004 